\title{
Human Antigen R Binding and Regulation of SOX2 mRNA in Human Mesenchymal Stem Cells ${ }^{\text {政 }}$
}

\author{
Elisa Latorre, Stephana Carelli, Filippo Caremoli, Toniella Giallongo, Mattia Colli, \\ Alessandra Canazza, Alessandro Provenzani, Anna Maria Di Giulio, and Alfredo Gorio \\ Laboratory of Pharmacology, Department of Health Sciences, University of Milan, Milan, Italy (E.L., S.C., F.C., T.G., M.C., A.M.D.G., \\ A.G.); Laboratory of Cell Biology, Cerebrovascular Diseases Unit, IRCCS Foundation Carlo Besta Neurological Institute, Milan, Italy \\ (A.C.); and Laboratory of Genomic Screening Center for Integrative Biology, University of Trento, Trento, Italy (A.P.)
}

Received July 8, 2015; accepted December 11, 2015

\section{ABSTRACT}

Since 2005, sex determining region y-box 2 (SOX2) has drawn the attention of the scientific community for being one of the key transcription factors responsible for pluripotency induction in somatic stem cells. Our research investigated the turnover regulation of SOX2 mRNA in human adipose-derived stem cells, considered one of the most valuable sources of somatic stem cells in regenerative medicine. Mitoxantrone is a drug that acts on nucleic acids primarily used to treat certain types of cancer and was recently shown to ameliorate the outcome of autoimmune diseases such as multiple sclerosis. In addition, mitoxantrone has been shown to inhibit the binding of human antigen $\mathrm{R}(\mathrm{HuR}) \mathrm{RNA}$-binding protein to tumor necrosis factor- $\alpha$ mRNA. Our results show that HuR binds to the $3^{\prime}-$ untranslated region of SOX2 mRNA together with the RNAinduced silencing complex miR145. The HuR binding works by stabilizing the interaction between the $3^{\prime}$-untranslated region and the RNA-induced silencing complex. Cell exposure to mitoxantrone leads to HuR detachment and the subsequent prolongation of the SOX2 mRNA half-life. The prolonged SOX2 half-life allows improvement of the spheroid-forming capability of the adipose-derived stem cells. The silencing of HuR confirmed the above observations and illustrates how the RNA-binding protein HuR may be a required molecule for regulation of SOX2 mRNA decay.

\section{Introduction}

Mesenchymal stem cells (MSCs) are multipotent fibroblastlike cells (Friedenstein et al., 1970), which have been extensively studied and found to be an excellent therapeutic tool for experimental cellular engineering (Caplan, 2007). MSCs are characterized by their self-renewal capability and multilineage differentiation (Dominici et al., 2006). Among the possible sources of MSCs, adipose tissue has become one of the most popular (Rosenbaum et al., 2008). In standard culture conditions, MSCs must be plastic adherent; must express surface molecules, such as CD105, CD73, CD90, and CD44; and must lack both hematopoietic and endothelial markers, such as CD45, CD14 or CD11b, CD79a or CD19, and major histocompatibility complex II (human leukocyte antigen-DR). When subjected to in vitro differentiation, MSCs

This research was supported by the Neurogel-en-March Foundation [(to A.G.)]. F.C. and T.G. are supported by the University of Milan doctorate program in biochemical sciences, nutritional and metabolic diseases. A.C. is supported by the University of Milan doctorate program in molecular and translational medicine.

E.L., S.C., and F.C. contributed equally to this work.

dx.doi.org/10.1124/mol.115.100701.

S This article has supplemental material available at molpharm. aspetjournals.org. can originate osteoblasts, adipocytes, and chondroblasts (Bourin et al., 2013).

Sex determining region y-box 2 (SOX2) is expressed by adult stem cells (Arnold et al., 2011), but the regulatory mechanisms underlying its expression are only partially understood. SOX2 expression and function are crucial for MSC lineage determination and proliferation, whereas SOX2 inhibition affects growth and differentiation (Park et al., 2012). The importance of SOX2 in cell fate became clear with the finding that it is one of the four core transcriptional factors (Oct4, Sox2, Klf4, and c-Myc) whose induced expression switches regular fibroblasts into pluripotent stem cells (Takahashi and Yamanaka, 2006; Takahashi et al., 2007; Yu et al., 2007). ELAVL1 [(embryonic lethal, abnormal vision)like 1 protein also known as human antigen $\mathrm{R}(\mathrm{HuR})$ ] has been implicated in the regulation of the cell cycle, cell migration, tumorigenesis, apoptosis, immunity, inflammation, and angiogenesis (Katsanou et al., 2009; Abdelmohsen and Gorospe, 2010; Gorospe et al., 2011). HuR can also affect progenitor cell survival in genetic ablated mice and its postnatal global deletion induces generalized body atrophy and lethality within 10 days (Ghosh et al., 2009). ELAVL1 is expressed ubiquitously and binds to AU-rich element- and U-rich

ABBREVIATIONS: $\alpha$-MEM, $\alpha$-minimum essential medium; BIX01294, N-(1-benzylpiperidin-4-yl)-6,7-dimethoxy-2-(4-methyl-1,4-diazepan-1-yl) quinazolin-4-amine; FACS, fluorescence-activated cell sorting; GAPDH, glyceraldehyde-3-phosphate dehydrogenase; HuR, human antigen R; miRNA, microRNA; MSC, mesenchymal stem cell; MTX, mitoxantrone; PCR, polymerase chain reaction; PMA, phorbol 12-myristate 13-acetate; RISC, RNA-induced silencing complex; UTR, untranslated region; ELAVL1, embryonic lethal, abnormal vision-like 1 porotein; CID, PubChem Compound Identification; KD, knock down. 
element-containing mRNAs (Abdelmohsen et al., 2007). Precisely, HuR binds to the $3^{\prime}$-untranslated region (UTR) of mRNAs, with regulation of activity on transcript stability and translation (Zucal et al., 2015), both by acting as an mRNA stabilizer and turnover enhancer. This occurs through the recruitment of the RNA-induced silencing complex (RISC) constituted by mature microRNAs (miRNAs) associated with GW182 and argonaut proteins (Chang et al., 2010). RISC may affect gene expression by binding to partially complementary sequences in the $3^{\prime}$-UTR of target mRNAs (Nishi et al., 2013). Murine HuR appears essential for life (Chi et al., 2011). However, its in vivo functions are not yet sufficiently understood. Notably, in the HuR-deleted mouse model, progenitor cells undergo apoptosis, whereas quiescent stem cells and differentiated cells remain unaffected. In this context, the SOX2 mRNA level is upregulated (Ghosh et al., 2009).

In this study, we investigate HuR function in human adipose MSCs and demonstrate its activity as a turnover regulator of the SOX2 gene transcript. Our study also demonstrates the functional interaction between $\mathrm{HuR}$ and RISC in this context.

\section{Materials and Methods}

Chemicals and Antibodies. The following chemicals were used at the indicated time points: isonicotinamide $(10 \mu \mathrm{M}$ for 4 hours, PubChem Compound Identification (CID) 15074; Tocris Bioscience, Bristol, UK), sodium phenylbutyrate (10 $\mu \mathrm{M}$ for 4 hours, CID 5258; Tocris Bioscience), BIX01294 [ $N$-(1-benzylpiperidin-4-yl)-6,7dimethoxy-2-(4-methyl-1,4-diazepan-1-yl) quinazolin-4-amine] (10 $\mu \mathrm{M}$ for 4 hours; CID 25150857; Tocris Bioscience), mitoxantrone (MTX) (1 nM for 4 hours, CID 51082; Sigma-Aldrich, St. Louis, MO), phorbol12-myristate-13-acetate (PMA) (500 nM for 4 hours, CID 27924; SigmaAldrich), cycloheximide ( $1 \mu \mathrm{M}$ for 16 hours, CID 6197; Sigma-Aldrich), and actinomycin-D (1 $\mu \mathrm{g} / \mathrm{ml}$, CID 2019; Sigma-Aldrich). The following antibodies were used: anti-HuR (SC-374285), anti-AGO2 (Argonaute 2, SC-53521), anti-SOX2 (SC-20088), and anti- $\beta$-actin (SC-47778; all from Santa Cruz Biotechnology, Santa Cruz, CA.

Human Fresh Lipoaspirated Adipose Tissue Isolation. Lipoaspirated adipose tissue was obtained from three healthy volunteers (one man and two women) after they reviewed and signed the institutional review board-approved written informed consent form. This study also conformed to the 2013 Declaration of Helsinki.

Adipose Tissue-Derived MSC Culture and Maintenance. Procedures for isolation and expansion of MSCs were conducted in a Biologic Safety Cabinet (BlueBeam4; Belstar, Tradate, Varese, Italy) and cells were cultured at $37^{\circ} \mathrm{C}$ in a humidified, $5 \% \mathrm{CO}_{2}$ incubator (Certomat CS-18; Sartorius Stedim Analytical Service, Cassina de' Pecchi, Milan, Italy). Approximately $2 \mathrm{ml}$ lipoaspirate adipose tissue was plated into T25- $\mathrm{cm}^{2}$ flasks (Corning, Corning, NY) with $\alpha$-minimum essential medium ( $\alpha$-MEM) (Euroclone, Pero, Milan, Italy) supplemented with $20 \%$ fetal bovine serum (Gibco, Life Technologies, Monza, Italy), 1\% penicillin/streptomycin solution (Gibco Life Technologies), and 1\% L-glutamine (Euroclone). After 2 weeks, the nonadherent fraction was removed and the adherent cells were cultured continuously. The medium was changed when the amount of cells covered about $50 \%$ of the flask bottom surface. When $80 \%-90 \%$ confluence was reached, cells were harvested by $0.05 \%$ trypsin/EDTA solution (Euroclone or Gibco Life Technologies), collected by centrifugation $(520 \times g$ for 5 minutes $)$, and reseeded in subconfluent condition (Carelli et al., 2015).

Cell Growth Analysis. Growth curve analyses were performed by counting the proliferative capacity of MSCs obtained from the lipoaspirated adipose tissue of three patients. Cells were maintained in culture in $\alpha$-MEM. The analyses were performed starting from cells at culture passage 2 . Cells were seeded onto 48-well culture plates
(Corning) and maintained in culture in growth medium. At 85\% confluence, live cells were counted by the Trypan blue (Sigma-Aldrich) exclusion test. Cell doubling times and cell doubling numbers were calculated from hemocytometer counts (Neubauer Chamber; VWR International, Radnor, PA). The analyses were performed at least three times for each point reported in the curve (Carelli et al., 2015).

G-Banding Karyotype Analysis. Cytogenetic analyses were performed on in situ cultures obtained by inoculating MSCs from lipoaspirate directly onto a coverslip inside petri dishes (Corning) containing $2 \mathrm{ml} \alpha$-MEM. Cells were treated with $0.02 \mu \mathrm{l} / \mathrm{ml}$ Colcemid (Life Technologies, Carlsbad, CA) for 90 minutes and then were treated with hypotonic solution (1:1 Na citrate $1 \%$ : NaCl $0.3 \%$ ) (SigmaAldrich) and a fixative solution of 3:1 methanol/acetic acid (VWR International Radnor), which was replaced twice. At least $25 \mathrm{QFQ}$ (Q-banding methods using quinacrine) banding metaphases were observed for each sample. The images were acquired using a fluorescence microscope (BX 60 Olympus) and analyzed with a Powergene PSI system.

Flow Cytometric Immunophenotypic Analysis. Cultures of MSCs from lipoaspirated adipose tissue at low passages were phenotypically characterized by fluorescence-activated cell sorting (FACS) (Table 1). After trypsinization and phosphate-buffered saline (PBS) $1 \times$ wash, $1 \times 10^{5}$ cells were resuspended in $250 \mu$ l PBS without $\mathrm{Ca}^{2+}$ and $\mathrm{Mg}^{+}$for 30 minutes at $4{ }^{\circ} \mathrm{C}$ in the dark for staining with the following antibodies: anti-CD44 (BD Biosciences, Milan, Italy), antiCD90 (Millipore, Milan, Italy), anti-CD34 (Mylteni Biotec, Bologna, Italy), anti-CD45 (BD Biosciences), anti-CD146 (Biocytex, Parsippany, NJ), anti-CD31 (Mylteni Biotec), anti-CD56 (Mylteni Biotec), anti-CD105 (AbD Serotec, Raleigh, NC), anti-CD144 (R\&D Systems, Minneapolis, MN), anti-CD166 (BD Biosciences), anti-CD133/2 (Mylteni Biotec), anti-CD73 (BD Biosciences), and anti-vascular endothelial growth factor receptor 2 (R\&D Systems). Samples were fixed with $4 \%$ paraformaldehyde (Sigma-Aldrich) and then analyzed by flow cytometry (FACS Vantage; BD Biosciences) using CellQuest Pro software (BD Biosciences). For negative controls, primary antibodies were omitted. After centrifugation with $1 \mathrm{ml}$ PBS $1 \times$ at $1300 \times g$ for 10 minutes, cells were fixed with $4 \%$ paraformaldehyde (SigmaAldrich) and approximately $5 \times 10^{3}$ events were acquired for each sample. Nonviable cells were excluded according to the side scatter versus forward scatter parameters. The results of the analysis are expressed as means \pm S.D.

Neural Stem Cell Isolation and Culture. Neural stem cells were isolated from the subventricular zone of adult mice brain (Gritti et al., 2002). Their maintenance in culture, differentiation, and immunostaining were performed as previously described (Carelli et al., 2015).

Indirect Immunofluorescence of MSCs. Cells seeded onto glass slides $\left(3.5 \times 10^{3}\right.$ cells $\left./ \mathrm{cm}^{2}\right)$ and grown until $85 \%$ confluence were fixed with $4 \%$ paraformaldehyde. After saturation (4\% bovine serum albumin and 0.3\% Triton X-100; (Sigma-Aldrich and VWR International, respectively) and permeabilization, cells were incubated overnight at $4^{\circ} \mathrm{C}$ with primary antibodies against human Nestin (clone

TABLE 1. FACS Analysis

\begin{tabular}{lc}
\hline Marker & Mean \pm S.D. \\
\hline CD31 & $5.45 \pm 6.85$ \\
CD34 & $1.6 \pm 0.71$ \\
CD45 & $2.2 \pm 1.7$ \\
CD133/2 & $0.5 \pm 0$ \\
CD44 & $97.0 \pm 3.8$ \\
CD56 & $2.15 \pm 0.07$ \\
CD73 & $96.8 \pm 4.24$ \\
CD90 & $87.2 \pm 2.54$ \\
CD105 & $93.1 \pm 3.96$ \\
CD144 & $16.0 \pm 18.52$ \\
CD146 & $21.15 \pm 21.0$ \\
CD166 & $91.0 \pm 2.54$ \\
KDR & $3.1 \pm 0.14$ \\
\hline
\end{tabular}


196908; R\&D Systems), Vimentin (polyclonal; Santa Cruz Biotechnology), GFAP (Glial fibrillary acidic protein, polyclonal; Covance, Princeton, NJ), and HuR (Santa Cruz Biotechnology). Cells were rinsed and then probed 45 minutes with secondary antibodies Alexa Fluor 488 or 543 anti-mouse, anti-rabbit, or anti-goat (Invitrogen, Carlsbad, CA). Nuclei were counterstained with 4',6-diamidino-2phenylindole $(2 \mu \mathrm{g} / \mathrm{ml}$ in PBS; Sigma-Aldrich), and glasses were mounted with FluorSave (Millipore, Billerica, MA). Images were taken using a Leica SP2 confocal microscope with $\mathrm{He} / \mathrm{Kr}$ and Ar lasers (Leica, Heidelberg, Germany). In negative control experiments, primary antibodies were replaced with equivalent concentrations of unrelated IgG of the same subclass.

RNA Immunoprecipitation. RNA immunoprecipitation was performed as reported in Latorre et al. (2012). RNA was isolated from the different samples (immunoprecipitated anti-HuR, IgG, and precleared input) by TRIzol reagent (Invitrogen) per the manufacturer's recommendations, retrotranscribed into cDNA by a MBI-Fermentas kit, and used as a template for polymerase chain reaction (PCR) analysis.

Quantitative Real-Time PCR Quantification of mRNAs. Total RNA from cultured cells and tissue samples was isolated using TRIzol reagent. RNA quality was ascertained using a spectrophotometer and visualized on agarose gel.

Total RNA $(1 \mu \mathrm{g})$ was reverse transcribed using an iScript cDNA synthesis kit (Bio-Rad, Segrate, Milan, Italy) according to the manufacturer's instructions. Quantitative real-time PCR was performed with an DNA engine OPTICON2 detection system
(MJ Research, Waltham, MA) using iQ SYBR Green Supermix (Bio-Rad) and primers for the following: SOX2 (forward: AGATAAACATGGCAATCAAAATG; reverse: CAACGGTGTCAACCTGCATGGCC), 18S (forward: GGCCCTGTAATTGGAATGAGTC; reverse: CCAAGATCCAACTACGAGCTT), HOTAIR (forward: ACGGAACCCATGGACTCATA; reverse: TGGTCCCATTTGGATCTTTC), and glyceraldehyde-3-phosphate dehydrogenase (GAPDH) (forward: AGCCACATCGCTCAGACAC; reverse: GCCCAATACGACCAAATCC).

DOT Blot. Samples were blotted onto an Immobilon polyvinylidene difluoride membrane (Millipore Corporation, Billerica, MA) with a PR600 slot blot manifold (GE Healthcare, Little Chalfont, UK), and blotting was performed with anti-SOX2 (S9072; Sigma-Aldrich) and anti-actin- $\beta$ (SC8432; Santa Cruz Biotechnology) as previously described (Latorre et al., 2012). Densitometry analysis of the bands was performed by ImageJ software (National Institutes of Health, Bethesda, MD).

Spheroid Formation. MSCs were grown in $\alpha$-MEM supplemented with $20 \%$ fetal bovine serum to reach $85 \%$ confluence at low passages $(<6)$. After trypsinization, cells were seeded into a six-well plate $\left(1.5 \times 10^{4}\right.$ cells $\left./ \mathrm{cm}^{2}\right)$ in neurosphere medium, containing basic fibroblast growth factor $(20 \mathrm{ng} / \mathrm{ml})$ and epidermal growth factor $(10 \mathrm{ng} / \mathrm{ml})$ and without serum (Carelli et al., 2015).

Gene Silencing and Overexpression. MSCs were silenced for HuR using Mission Lentiviral Transduction Particles (Sigma-Aldrich) according to the manufacturer's instructions. HuR was overexpressed by transient transfection of the pCMV6-AC-Myc-His-HuR (D'Agostino et al., 2013), miR145 by transient transfection of the
A

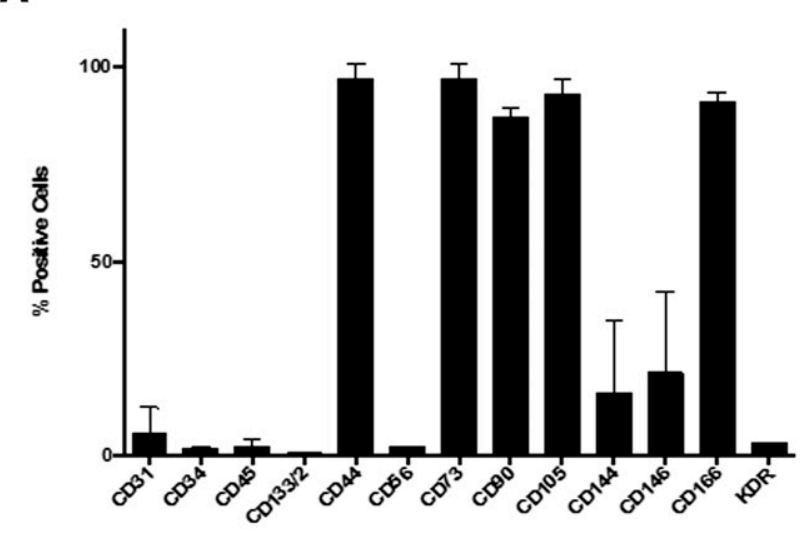

C

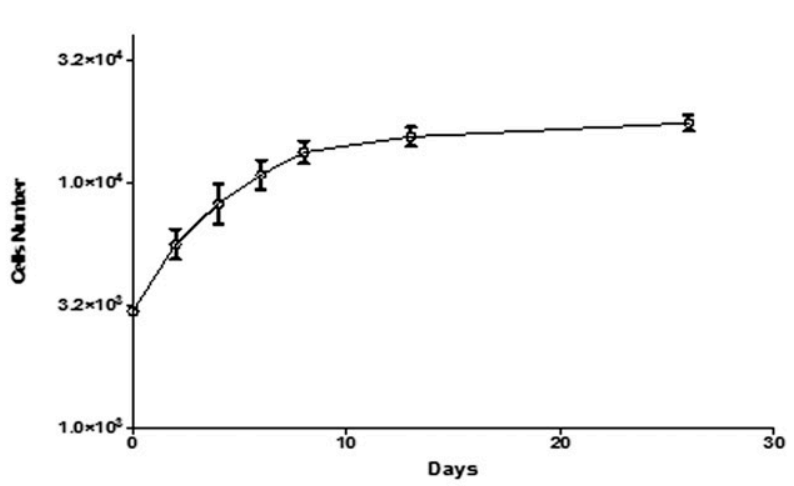

B
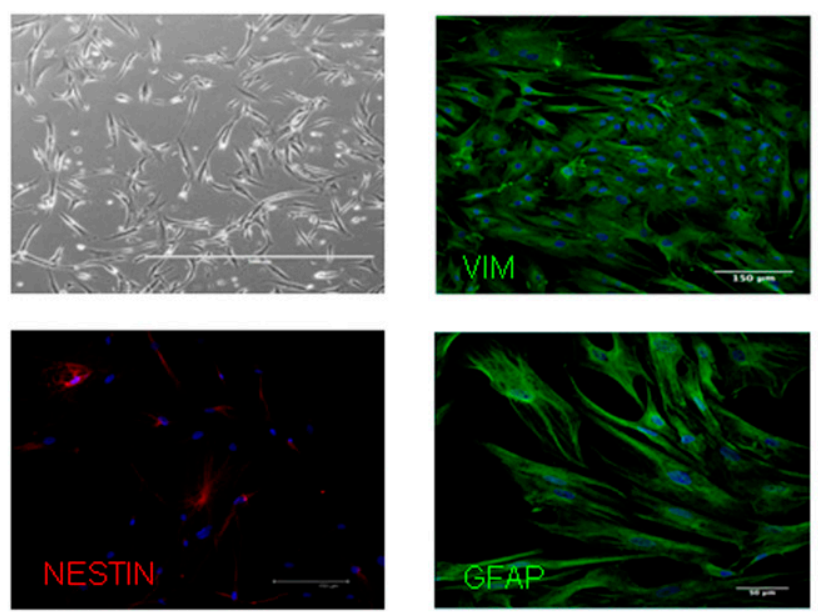

D

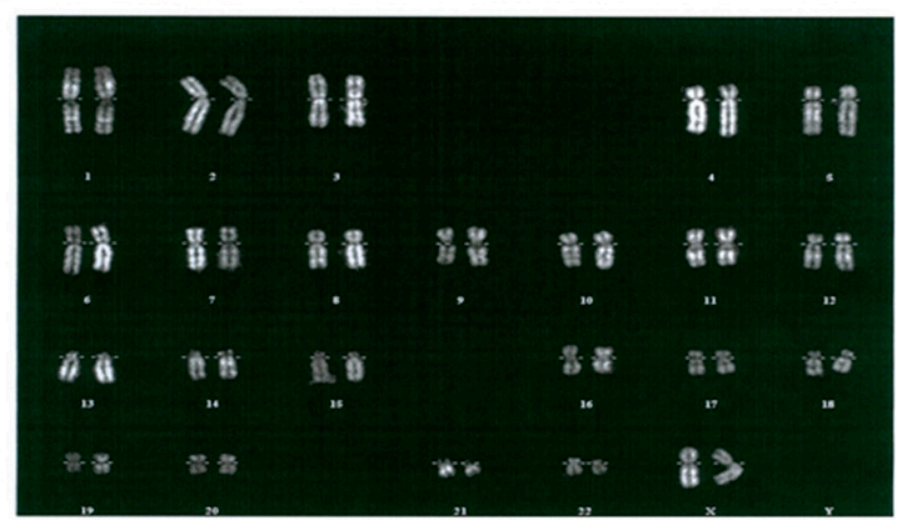

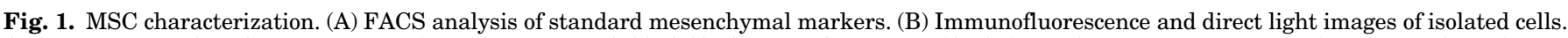

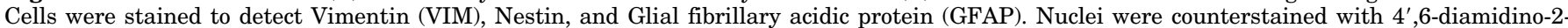
phenylindole (blue). (C) Cell counts are expressed as total cell number at the different culture days. (D) Karyotype analysis performed at passage 5. 


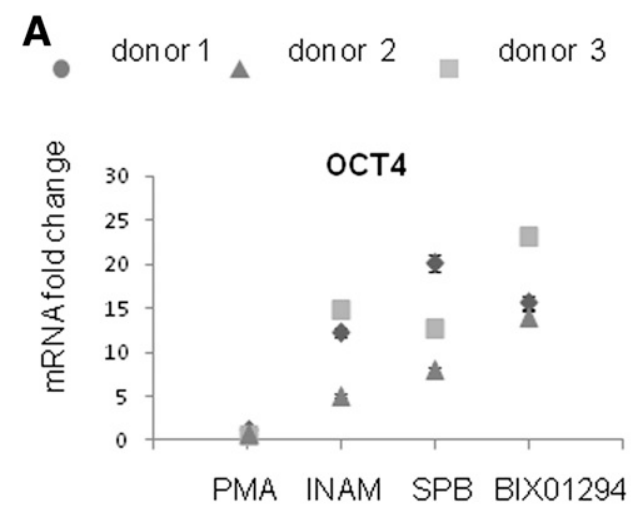

PMA INAM SPB BIX01294
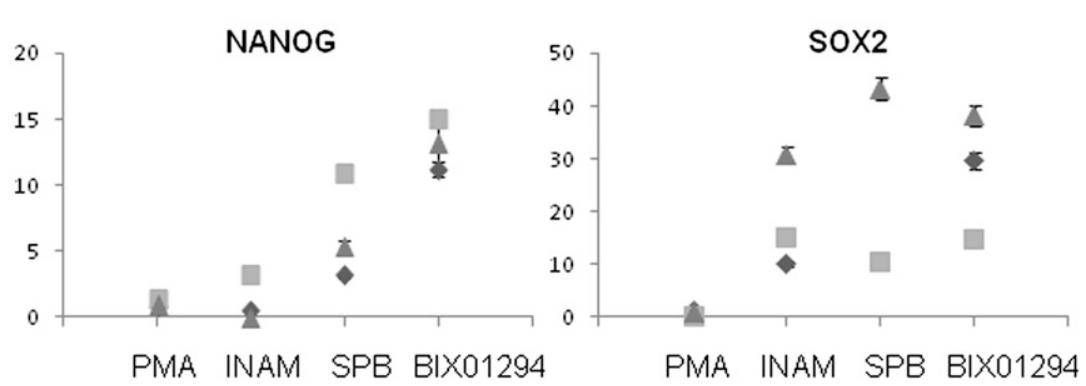

$\alpha=0,01$

B

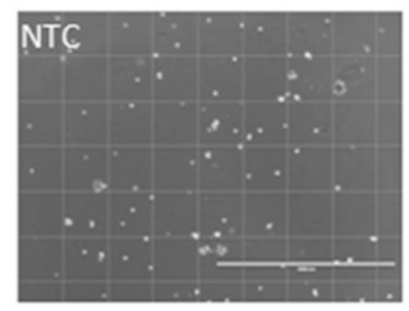

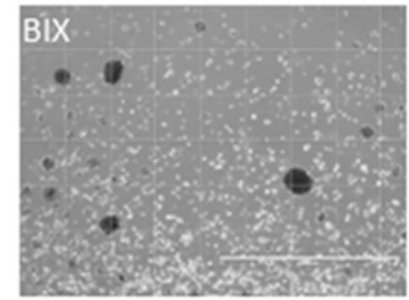

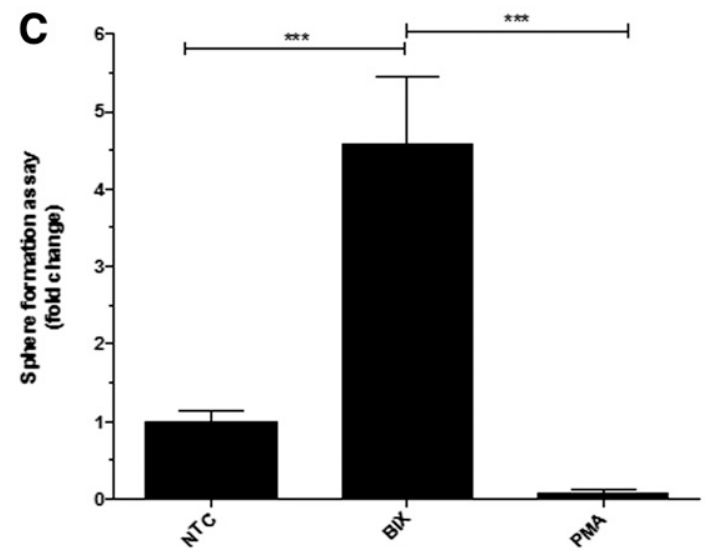

Fig. 2. MSC exposure to epigenetic drugs. (A) Quantitative reverse-transcription PCR to monitor SOX2, OCT4, and NANOG mRNA expression levels in MSCs isolated from three different healthy donors. Markers were investigated in presence or absence of pharmacological treatments for 4 hours with PMA (500 nM), INAM (10 $\mu \mathrm{M})$, SPB $(10 \mu \mathrm{M})$, and BIX $(10 \mu \mathrm{M})$. Results were expressed as fold change relative to untreated cells. Each point was analyzed in triplicate. (B) Direct light picture of a spheroid obtained from MSC exposed for 4 hours (BIX; $10 \mu \mathrm{M}$ ) or not (NTC) to BIX01294. (C) Spheroid assay. The histogram reports the number of spheroids obtained from MSC exposed (BIX) or not (NTC) to BIX01294 and results are expressed as the fold change of spheroid number relative to the NTC. ${ }^{* * *} P<0.01$. BIX, BIX01294; INAM, isonicotinamide; SPB, sodium phenyl butyrate. Bar, $100 \mu \mathrm{m}$.

commercially available miRNA (Sigma-Aldrich). AGO2 was silenced by transient transfection of commercially available siRNA (SC-44409; Santa Cruz Biotechnology). Transfection was performed using Lipofectamine 2000 (Invitrogen) as recommended by the manufacturer.
hSOX2 mRNA Mutagenesis. The SOX2 (NM_003106) 3'-UTR cloned in pMirTarget (Origene, Rockville, MD) was mutagenized using the following primers: FW1: tgtccCCCCCCCataagctgagaaCttgccaatattttc; Rev1: GAAAAATATTGGCAAGTTCTCAGCTTATGGGGGGGGGACA; FW2: gttttagactgtactaaatCCCCCCCcttactgtCaaaagc;
A

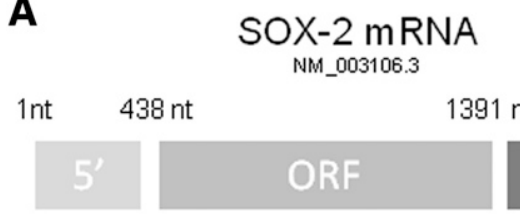

B

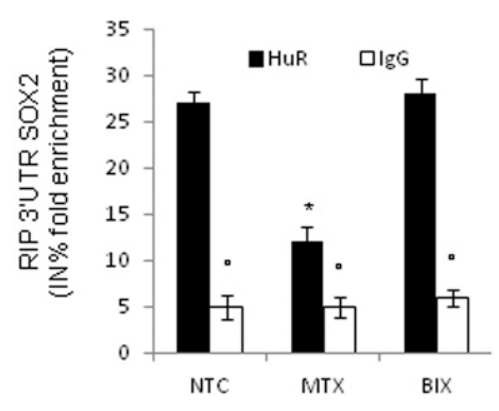

\section{AU-rich region}
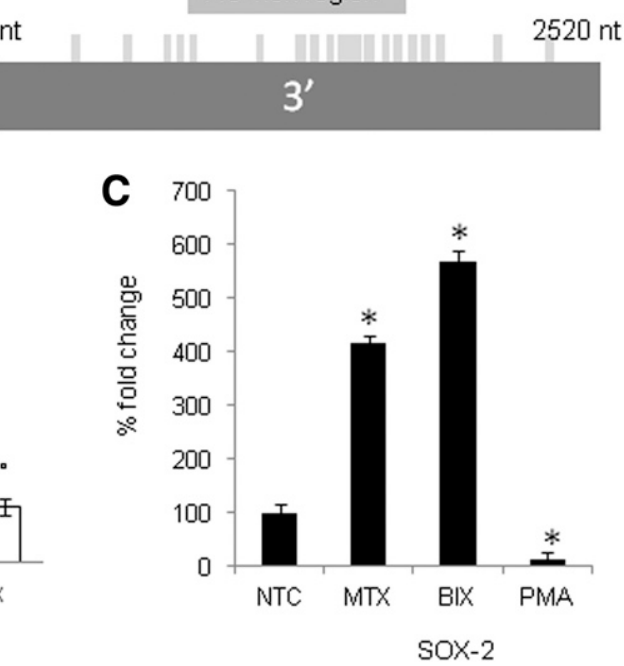

Fig. 3. HuR binding to SOX2 mRNA. (A) SOX2 mRNA scale representation of the different regions. The AU-rich region is reported in gray bar. The mRNA sequence pictured as divided into $3^{\prime}$-UTR, open reading frame (ORF), and 5'-UTR region. (B) RNA immunoprecipitation against HuR (black bar), reported as IN\% fold enrichment. Cells were treated or not (NTC) with MTX (1 nM) or BIX01294 $(10 \mu \mathrm{M})$. Preimmunization serum was used as precipitation negative control (IgG, white bar). $* P<0.01$, HuR sample versus HuR NTC; ${ }^{\circ} P<0.01$, HuR sample versus IgG sample. (C) SOX2 mRNA expression level in the presence or absence of MTX (1 nM), BIX01294 $(10 \mu \mathrm{M})$, and PMA (500 $\mathrm{nM})$ treatment for 4 hours. Results were expressed as fold change percentage. ${ }^{*} P<0.01$ treated versus untreated. BIX, BIX01294. 
Rev2: GCTTTTGACAGTAAGGGGGGGGATTTAGTACAGTCTAAAAC; FW3: gacaccgttggtaaCCCCCCCtagcttttgttcgatc; and Rev3: GATCGAACAAAAGCTAGGGGGGGTTACCAACGGTGTC

Luciferase Activity. The Pierce Firefly Luciferase Flash Assay Kit (Sigma-Aldrich) was used according to the manufacturer's instructions 24 hours after transfection with Lipofectamine 2000 (Invitrogen).

Statistical Analysis. Data are expressed as means \pm S.D. Two-way analysis of variance and Bonferroni's post test were applied using Prism 5 software (GraphPad Software Inc., La
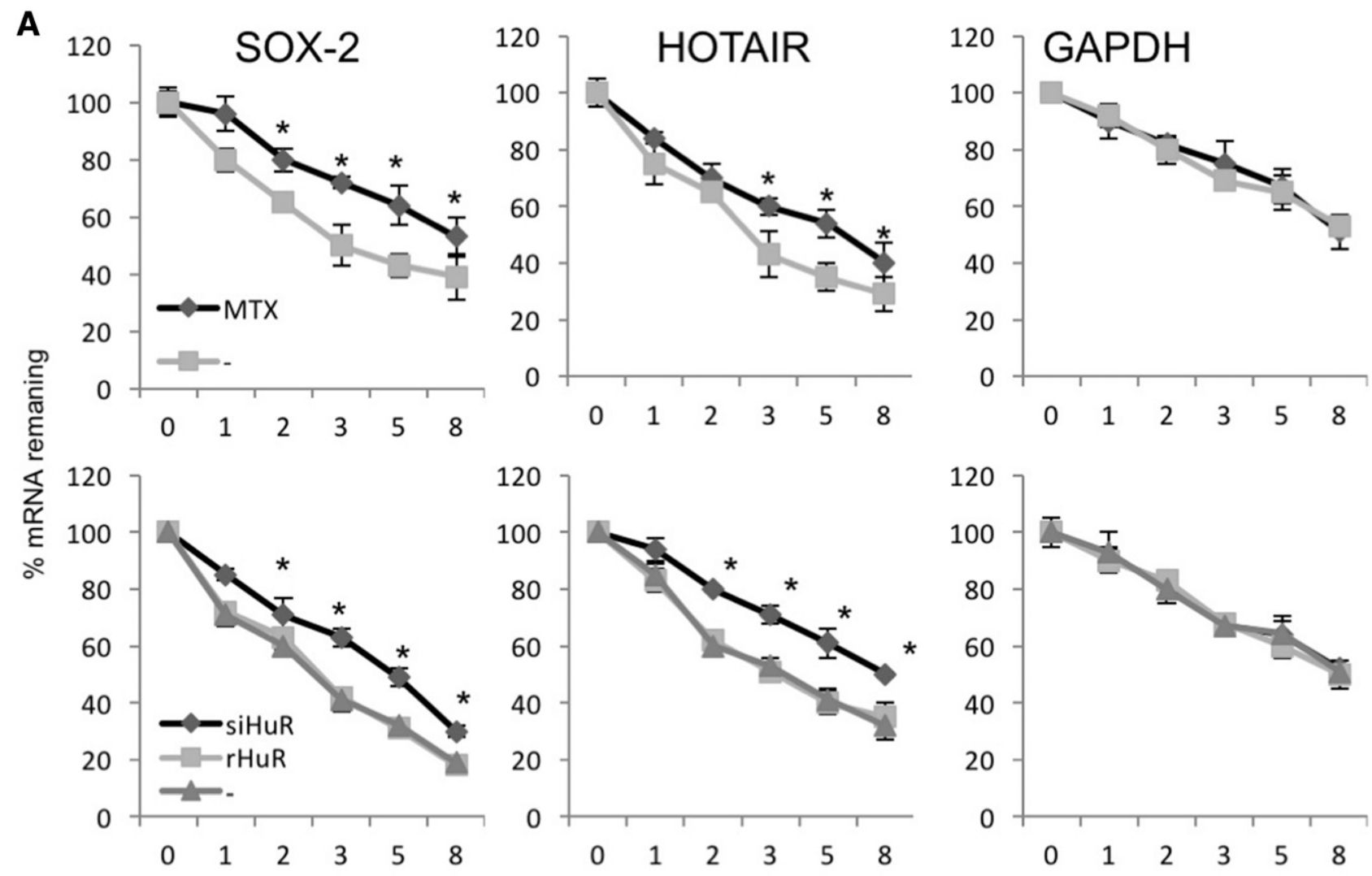

B

hours post actinomycin-D
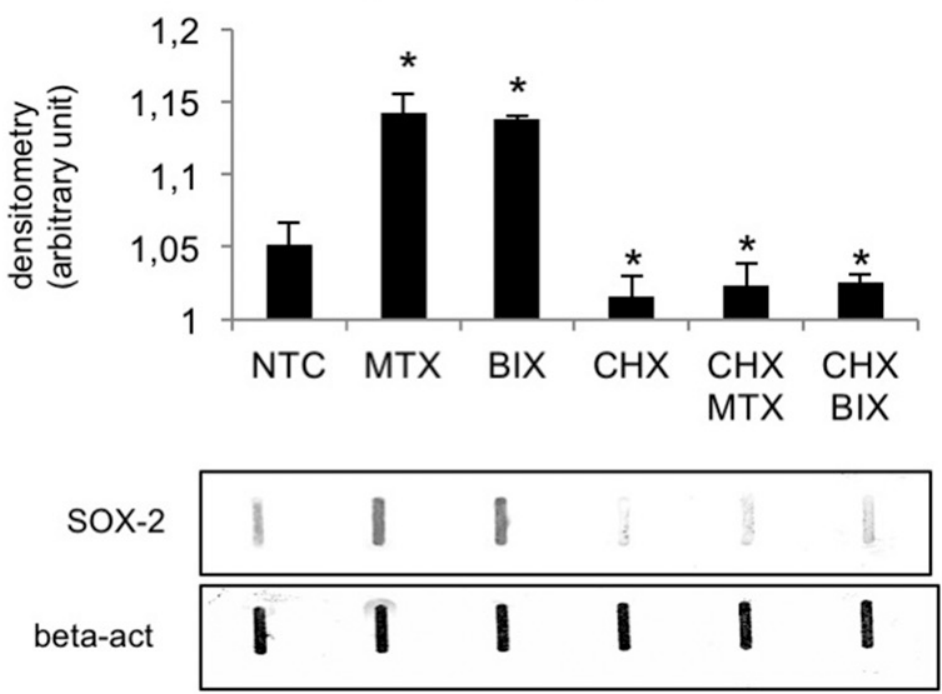

Fig. 4. HuR regulates SOX2 mRNA turnover. (A) RNA de novo synthesis blockade. MSCs were treated with actinomycin-D (1 $\mu \mathrm{g} / \mathrm{ml})$ for 8 hours and SOX2, HOTAIR, and GAPDH RNA expression levels were measured in the presence or absence of MTX (1 nM) and after HuR silencing (siHuR) or overexpression $(\mathrm{rHuR})$. Levels were reported as a percentage of remaining mRNA. $* P<0.01$, treated versus untreated. (B) SOX2 protein expression and de novo protein synthesis inhibition. The histogram shows densitometry analysis performed on dot blot against SOX2. $\beta$-Actin was used as the loading control. Cells were treated or not with MTX $(1 \mathrm{nM})$, BIX01294 $(10 \mu \mathrm{M})$ for 4 hours, and cycloheximide $(1 \mu \mathrm{M})$ for 16 hours. MTX and BIX upregulated SOX2 protein expression and cycloheximide blocked this upregulation in both cases. ${ }^{*} P<0.01$, treated versus untreated. beta-act, $\beta$-actin; BIX, BIX01294; CHX, cycloheximide. 
Jolla, CA) assuming a $P$ value less than 0.05 as the limit of significance.

\section{Results}

MSC Isolation and Characterization. MSCs were isolated from human adipose tissue (three healthy donors) without enzymatic digestion and maintained in culture as described in the Materials and Methods (Araña et al., 2013; Canazza et al., 2015; Carelli et al., 2015). Specific mesenchymal markers were identified by FACS (Fig. 1A), whereas the expression of specific proteins such as VIMENTIN, NESTIN, and GFAP was assessed by immunofluorescence (Fig. 1B). The observed proliferation rate demonstrated a steady growth in cell number for about 2 weeks in culture after plating (Fig. 1C). The karyotype did not reveal any aberrant malignant cell transformation during the experimental observation period (Fig. 1D).

Effects of Drug-Induced Epigenetic Reprogramming. MSCs were exposed for 4 hours to three well known epigenetic reprogramming drugs, including isonicotine amide $(10 \mu \mathrm{M})$, sodium phenyl butyrate $(10 \mu \mathrm{M})$, and BIX01294 $(10 \mu \mathrm{M})$ (Shi et al., 2008). PMA (500 nM) was used as a negative control, since it promotes differentiation (Huberman and Callaham, 1979). The expression of SOX2, OCT4, and NANOG, assessed by quantitative real-time reverse-transcription PCR, increased after exposure to the epigenetic reprogramming drugs (Fig. 2A). Aiming at the generation of spheroids, MSCs were plated in neurosphere medium, a serum-free medium commonly used for promoting the proliferation of neural stem cells and the formation of neurospheres (Feng et al., 2014; Carelli et al., 2015; Yang et al., 2015). We plated $1.5 \times 10^{4}$ cells $/ \mathrm{cm}^{2}$, and spheres were gradually formed during the culture period of 10 days (Fig. 2B). Although the PMA abolished spheroid formation by MSCs, 4 hours of exposure to BIX01294 $(10 \mu \mathrm{M})$ significantly augmented formation of MSC spheroids without affecting cell vitality (Fig. 2C; Supplemental Fig. 1).

HuR Binding to SOX2 mRNA. SOX2 decay is crucial in stemness maintenance (Zappone et al., 2000). Using the
A

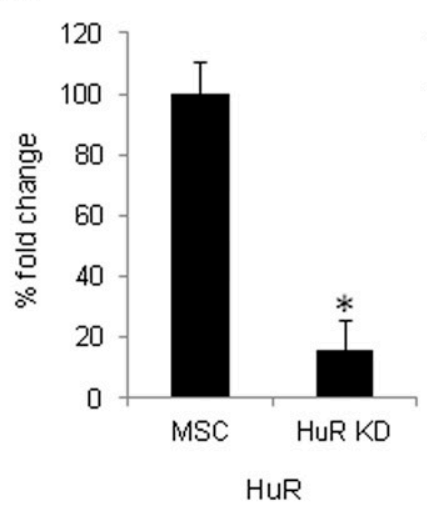

B

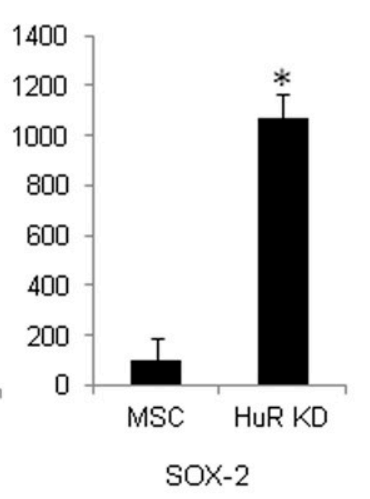

B

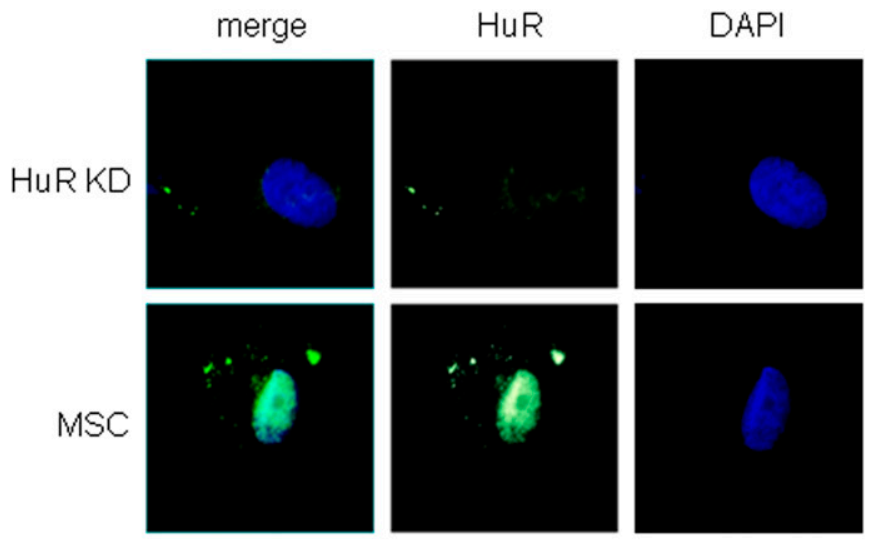

C

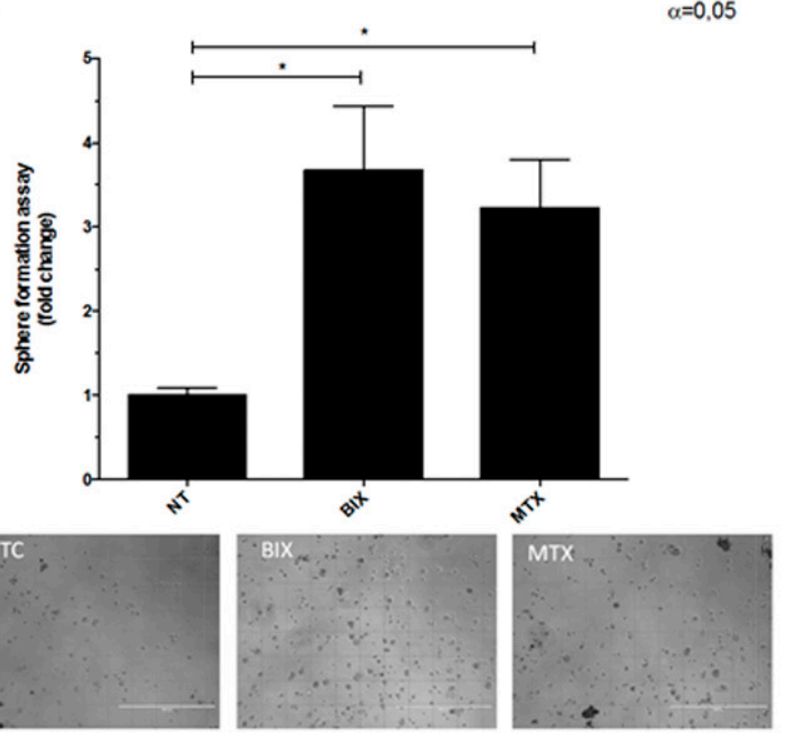

Fig. 5. HuR silencing and inhibition induces SOX2 upregulation. (A) SOX2 mRNA expression level in presence (HuR KD) or absence of HuR silencing (MSC). Results were expressed as fold change percentage. $* P<0.01$. (B) HuR immunofluorescence on MSCs silenced (HuR KD) or not (MSC) for HuR expression. HuR is in green and DAPI (blue) was used as the counterstain. (C) Spheroid assay. Direct light picture of spheroid obtained from MSCs exposed or not (NTC) to BIX01294 (10 $\mu$ M) or MTX (1 nM) for 4 hours. The histogram reports the number of spheroids obtained from MSCs exposed (BIX, MTX) or not (NTC) to BIX01294 or MTX. Results are expressed as fold change of spheroid number relative to the NTC. $* P<0.01$. Bar, $100 \mu \mathrm{m}$. BIX, BIX01294; DAPI, 4',6-diamidino-2-phenylindole. 
Database of RNA-Binding Protein Specificities online tool (http://rbpdb.ccbr.utoronto.ca/index.php), we predicted in silico the presence of the binding site for HuR, which binds to mRNAs at the AU-rich elements and regulates transcript stability and translation (Ghosh et al., 2009). This binding is essential for progenitor cell survival and overall embryogenesis in mice (Katsanou et al., 2009). However, the mechanisms underlying $\mathrm{HuR}$ in vivo action are not yet fully understood.

The sequence reported in Fig. 3A and Supplemental Fig. 2 depicts the presence of HuR binding sites (gray highlight) in SOX2 mRNA as predicted in silico. These would be located within the $3^{\prime}$-UTR region of the mRNA molecule (Fig. 3A; Supplemental Fig. 2). We tested HuR binding to the 3 '-UTR of SOX2 mRNA by RNA immunoprecipitation analysis (Fig. 3B). This resulted in a positive binding signal in the normal condition. However, when cells were exposed to MTX (a drug known to inhibit HuR binding to RNA molecules; D'Agostino et al., 2013), a reduction in immunoprecipitated RNA was observed, suggesting that a significant detachment of $\mathrm{HuR}$ from the RNA molecule had occurred. Conversely, cells treated with BIX01294 did not display HuR binding impairment to SOX2 mRNA (Fig. 3B). When the total SOX2 messenger was assessed, we observed an upregulation induced by both MTX and the reprogramming drug BIX01294, whereas the prodifferentiating agent PMA caused a downregulation, as expected (Fig. 3B) (Divya et al., 2012). Moreover, the ability of MTX in inducing SOX2 mRNA upregulation was also assessed in non-MSCs (adult neural stem cells), with a similar outcome (Supplemental Fig. 3).

HuR Facilitates SOX2 mRNA Degradation. Blocking de novo mRNA synthesis by treating cells with actinomycin-D (Koba and Konopa, 2005) resulted in a gradual SOX2 mRNA decay. Since the HuR and RISC complex has been shown to be involved in the stabilization of HOTAIR RNA (Yoon et al., 2013), we inserted HOTAIR as a positive control of the assay. The RNA turnover was significantly slower when MTX was present in the medium (Fig. 4A). This result suggests that HuR may play a role in SOX2 mRNA turnover similar to the role played on HOTAIR linc-RNA, linc-p21, and c-MYC mRNA. We assessed the key role of HuR in SOX2 mRNA stabilization by knocking down (siHuR) or overexpressing $(\mathrm{rHuR})$ the protein. We observed that SOX2 mRNA was more stable when the expression level of HuR had been lowered (Fig. 4B). Conversely, the overexpression of the RNA-binding protein did not influence SOX2 mRNA stability (Fig. 4B). Protein expression levels were monitored by dot blot analysis in protein extracts obtained from MSCs treated or untreated with MTX or BIX01294 (positive control). The data shown in
A

colP.: IN IgG AGO2 HuR

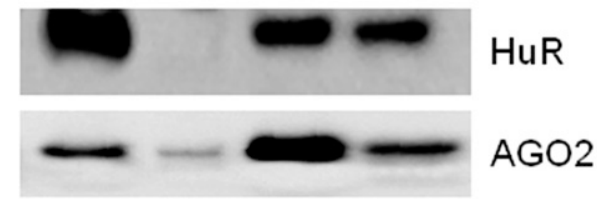

B

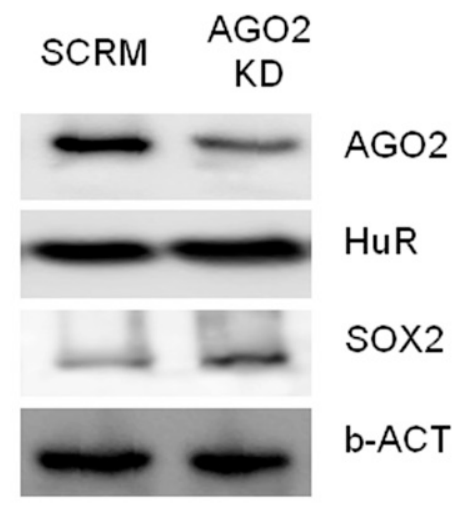

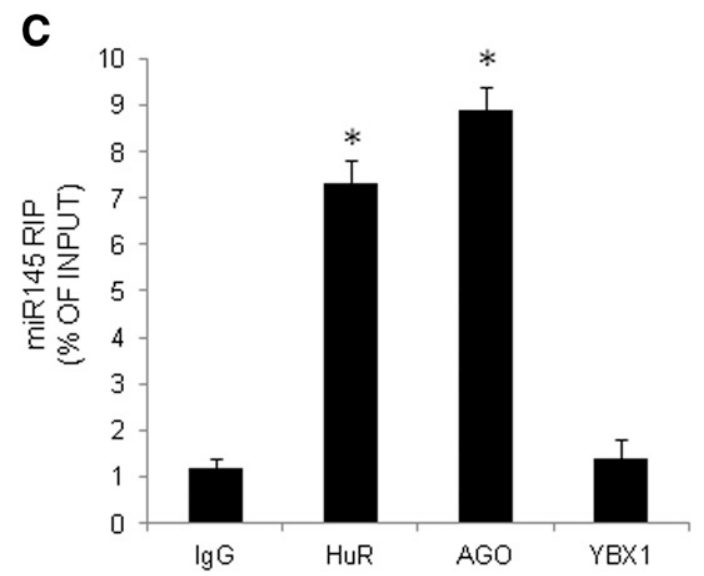

D

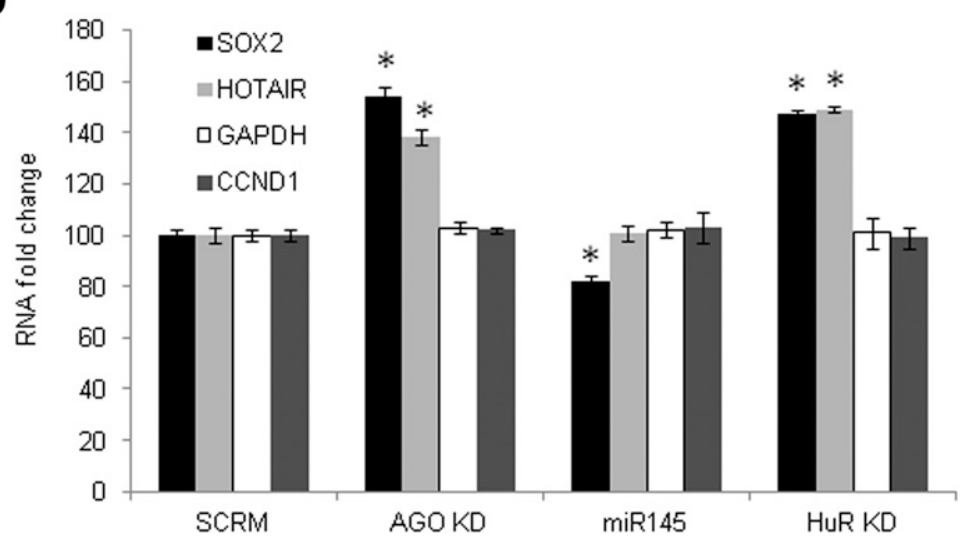

Fig. 6. HuR stabilizes the RISC-miR145 complex on the 3'-UTR of SOX2 mRNA. (A) Coimmunoprecipitation on MSCs to detect HuR and AGO2 interaction. Preimmune whole serum IgG or an unrelated RNA-binding protein (YBX1) was used as negative control. Input whole cell lysate was used as the positive control. ${ }^{*} P<0.01$, sample versus IgG sample. Western blotting against AGO2, HuR, and SOX2 in the presence (AGO2 KD) or absence (SCRM) of AGO2 silencing. Probing against $\beta$-actin was used as loading control. (B) RNA immunoprecipitation assay to detect the interaction between miR145 and the two proteins of interest, HuR and AGO2. YBX1 is an unrelated RNA-binding protein used as negative control. (C) RNA expression level of SOX2 (black bar), HOTAIR (light gray bar), GAPDH (white bar), and CCND1 (dark gray bar) tested in normal MSCs (SCRM), after AGO2 silencing (AGO $\mathrm{KD}$ ), after miR145 overexpression (miR145), or after HuR silencing (HuR KD). Results were expressed as fold change percentage. $* P<0.01$, SCRM versus treatments. b-ACT, $\beta$-actin; coIP, coimmunoprecipitation; IN, Input. 
Fig. 4C suggest that MTX treatment of MSCs can influence SOX2 de novo protein synthesis. SOX2 protein upregulation is induced by MTX and BIX01294 through mRNA stabilization and epigenetic regulation, respectively. As a control, cycloheximide ( $1 \mu \mathrm{M}$ for 16 hours), an inhibitor of protein biosynthesis, was used (Obrig et al., 1971). Under these conditions, both pharmacological treatments resulted in the abrogation of the SOX2 protein level (Fig. 4C).

HuR Ablation Results in SOX2 Upregulation. To demonstrate the role of HuR in SOX2 mRNA stabilization, we genetically ablated HuR expression in MSCs by lentiviral transduction. HuR silencing was validated by quantitative reverse-transcription PCR (Fig. 5A) and by immunofluorescence (Fig. 5B). Both methods exhibited a powerful reduction of HuR expression in silenced MSCs. Moreover, we showed that SOX2 mRNA is augmented in the absence of $\mathrm{HuR}$, as expected by the previously described results (Fig. 5A). To demonstrate that the SOX2 mRNA stabilization by MTX treatment modulates stemness, we performed a spheroid-forming assay. MSCs were plated in sphere-forming medium with or without MTX (1 nM) or BIX01294 (10 $\mu \mathrm{M})$, serving as the positive control. The 4-hour exposure to BIX01294 or MTX significantly enhanced the formation of MSC spheroids (Fig. 5C).

HuR Stabilizes the RISC-miR145 Complex on the $3^{\prime}$ UTR of SOX2 mRNA. We performed a coimmunoprecipitation assay between HuR and AGO2 (Sontheimer, 2005) to confirm the existence of the interaction between $\mathrm{HuR}$ and the RISC complex, in the context of SOX2 mRNA stabilization, as it was described for HOTAIR RNA (Yoon et al., 2013). Our results show that the two RNA-binding proteins do interact (Fig. 6A). As in the case of HuR knock down (KD), the downregulation of AGO2 expression leads to the overexpression of SOX2 (Fig. 6B).

miRNA molecules are also required for proper targeting of the RISC onto specific mRNA for degradation (Sontheimer, 2005). It has been shown that SOX2 mRNA is downregulated by the binding of miR145 and RISC (Wang et al., 2013) to the AU-rich region into its 3 '-UTR (Supplemental Fig. 2). In our experimental model, the presence of miR145 in the HuR/RISC complex was tested by the RNA immunoprecipitation assay, in which HuR and AGO2 are able to precipitate the miR145, whereas the unrelated RNA-binding protein YBX1 does not (Fig. 6C). Moreover, the overexpression of miR145 also induces SOX2 mRNA degradation in our model (Fig. 6D).

The specificity of the HuR/RISC/miR145 complex on the stabilization of SOX2 mRNA was assessed by investigating, in the same assay, the stability of CCND1, a well known HuR interacting mRNA (Lal et al., 2004), and GAPDH, a housekeeping mRNA. Both targeted mRNAs were not affected by the different experimental conditions (Fig. 6D).

HuR/RISC/miR145 Binding to the SOX2 3 '-UTR Is Necessary for mRNA Turnover. Fig. 7 reports results obtained in a reporter assay test in which the $3^{\prime}$-UTR of the SOX-2 mRNA was cloned downstream of the luciferase cDNA. The 3'-UTR was mutagenized by site-specific mutagenesis to ablate the AU-rich regions involved in HuR binding. miR145 is involved in AGO complex targeting and activation, and its binding site is on the AU-rich regions. In this manner, we investigated its activity on the reporter assay. The experiment was performed with or without $\mathrm{HuR}$ and AGO silencing, or with the MTX inhibitor of HuR binding to RNA molecules. The aim was to demonstrate the necessity of these target regions

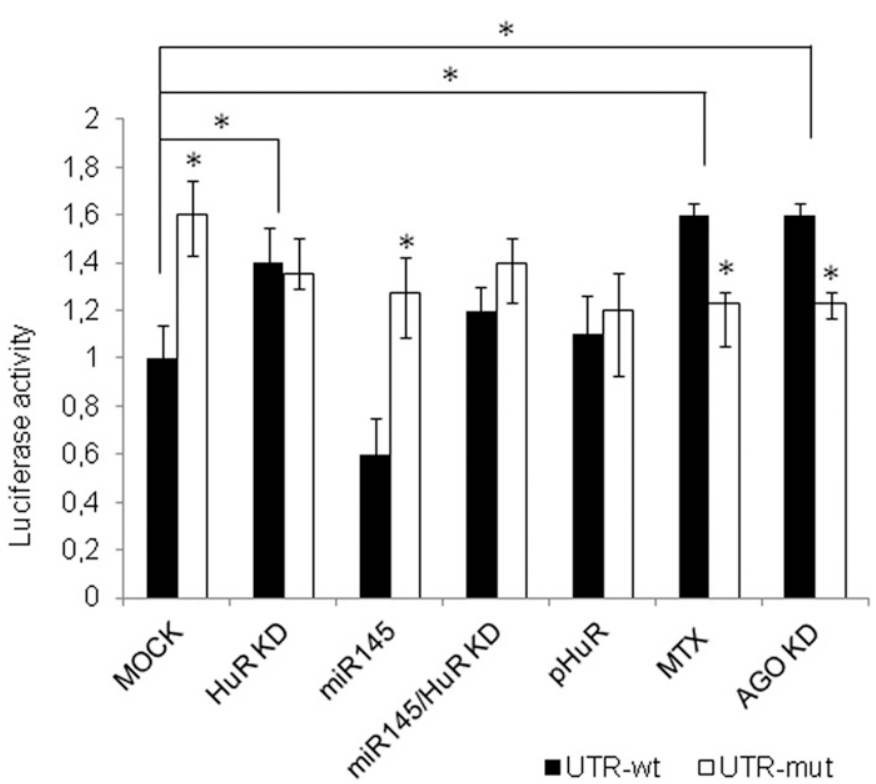

Fig. 7. The SOX2 $3^{\prime}$-UTR is targeted by the HuR/RISC complex. The role of the SOX2 3'-UTR was investigated by the luciferase reporter assay performed in MSCs transfected with the wild-type 3'-UTR reporter vector (UTR-wt; black bar) or the mutagenized 3'-UTR reporter vector (UTR-mut; white bar). Cells were silenced (HuR KD) or not (MOCK) for HuR expression or AGO2 (AGO KD), overexpressing HuR (pHuR), overexpressing (miR145), or treated with MTX ( $1 \mathrm{nM})$. The graph reports the luciferase activity renilla normalized relative to the wild type. ${ }^{*} P<0.01$.

and of $\mathrm{HuR}$ in AGO/miR145 RNA-driven degradation activity. In absence of HuR (HuR KD), SOX-2 mRNA is more stable, whereas miR145 overexpression leads to faster decay. When miR145 is overexpressed in the absence of HuR activity, there is no effective elicitation of SOX-2 mRNA decay (miR145/HuR KD). The addition of MTX ( $1 \mathrm{nM}$ for 4 hours) results in the stabilization of the SOX-2 mRNA through the detachment of HuR from its target, as observed above, after HuR silencing.

MTX and AGO silencing is generally more effective on mRNA stabilization of the wild-type 3 '-UTR compared with the mutagenized type, indicating a possible involvement of other mechanisms engaging the molecules.

\section{Discussion}

It is commonly accepted that MSCs may have relevant therapeutic potential in regenerative medicine, but improved understanding of the mechanisms underlying their fate and activity are needed. MSCs show fibroblast-like morphology in adherent cultures yet can differentiate along mesenchymal lineages. Reliable sources of stem cells associated with liable scaffolds and growth factors are still emerging needs of regenerative medicine (Gimble et al., 2007). Adipose tissue represents an abundant and accessible source of mesenchymal stromal cells with the ability to differentiate along multiple lineage pathways. Somatic cell reprogramming involves epigenetic modification, changes in gene expression, protein degradation, and protein synthesis. Despite recent remarkable progress in reprogramming technology, the underlying molecular mechanisms remain largely elusive. Several reports have recently shown that the early stage of cell reprogramming requires epigenetically regulated events, 
initiating rearrangement of gene expression profiles (Blancafort et al., 2013; Leu et al., 2013).

The transcription factors Oct4, Sox2, and Nanog are crucial components of the regulatory circuit in pluripotency states (Boyer et al., 2005; Chambers et al., 2007; Avilion et al., 2003). Moreover, recent reports have confirmed that Oct4 and Sox2 together with Klf4 and c-Myc can induce naïve or primed pluripotency in somatic cells according to the applied culture conditions (Yu et al., 2007; Han et al., 2013). SOX2 is a key stemness regulator (Patel and Yang, 2010; Arnold et al., 2011) expressed in embryonic and adult stem cells (Favaro et al., 2009), and it has been demonstrated that Sox2 is a determinant of reprogramming capacity, whereby its overexpression boosts the low reprogramming potential of epigenetic stem cells (Han et al., 2013).

Here we report that SOX2 mRNA turnover is regulated by the activity of RNA-binding protein HuR (a member of the ELAV/Hu family) on its $3^{\prime}$-UTR. HuR binds to the messengers at the $3^{\prime}$-UTR level, and such binding is essential for the action of the RISC. HuR stabilization activity on RISC was previously reported for the regulation of c-Myc transcript (Kim et al., 2009), linc-p21 long-noncoding RNA, or HOTAIR longnoncoding (Yoon et al., 2013). We additionally demonstrate that HuR, acting together with miR145, is necessary for stabilization of the RISC complex, which was reported as a miRNA essential for the SOX2 mRNA turnover (Wang et al., 2013). The specific binding site of miR145 is the AU-rich region targeted by $\mathrm{HuR}$ associated with RISC.

We also observed that HuR upregulation, above the physiologic expression level, has no effect on SOX2 mRNA decay (Supplemental Fig. 3, A and B), probably because of a preexisting saturation of the HuR binding sites by the endogenous protein, which is expressed at high levels by the cell.

The RNA Binding Protein HuR stabilizes and modulates the translation of numerous target mRNAs (Hinman and Lou, 2008). Our research indicates that through pharmacological inhibition of HuR RNA binding, by means of MTX (D'Agostino et al., 2013) or HuR genetic ablation, SOX2 mRNA is stabilized, accompanied by an increase in protein expression. These results support the strong role of $\mathrm{HuR}$ in SOX2 mRNA processing and turnover. Our results are in line with other evidence, which also reported the interaction of $\mathrm{HuR}$ with HOTAIR RNA (Yoon et al., 2013). These authors showed that HuR and the let-7 miRNA, together with RISC, repressed HOTAIR RNA through an inter-dependent mechanism, because let-7 required HuR to reduce HOTAIR expression. Our observations on SOX2 mRNA turnover and protein level regulation suggest a relevant role in tissue homeostasis and underline the importance of HuR in adult tissue stemness regulation. Sox2 signaling continues to be crucial in the biology of cells, because it is involved in the regulation of several endodermal and ectodermal tissues during fetal development, such as the nervous system (Bylund et al., 2003; Graham et al., 2003; Ellis et al., 2004), lens epithelium (Kamachi et al., 1998), anterior foregut endoderm (Que et al., 2007), and its derivatives, as well as sensory cells of the taste bud (Okubo et al., 2006), inner ear (Kiernan et al., 2005), and retina (Taranova et al., 2006). In conclusion, this report supplies new insights on $\mathrm{HuR}$ involvement in the regulation of stemness and in SOX2 expression in MSCs derived from human adipose tissue.

\section{Acknowledgments}

The authors thank Dr. Anthea De Angelis for outstanding technical support and Dr. Jovita Brantley for proofreading the article.

\section{Authorship Contributions}

Participated in research design: Latorre, Carelli, Provenzani, Gorio.

Conducted experiments: Latorre, Carelli, Caremoli, Giallongo, Colli, Canazza.

Performed data analysis: Latorre, Carelli, Caremoli, Giallongo.

Wrote or contributed to the writing of the manuscript: Latorre, Carelli, Di Giulio, Gorio.

\section{References}

Abdelmohsen K and Gorospe M (2010) Posttranscriptional regulation of cancer traits by HuR. Wiley Interdiscip Rev RNA 1:214-229.

Abdelmohsen K, Pullmann R, Jr, Lal A, Kim HH, Galban S, Yang X, Blethrow JD, Walker M, Shubert J, and Gillespie DA et al. (2007) Phosphorylation of HuR by Chk2 regulates SIRT1 expression. Mol Cell 25:543-557.

Araña M, Mazo M, Aranda P, Pelacho B, and Prosper F (2013) Adipose tissue-derived mesenchymal stem cells: isolation, expansion, and characterization. Methods Mol Biol 1036:47-61.

Arnold K, Sarkar A, Yram MA, Polo JM, Bronson R, Sengupta S, Seandel M, Geijsen $\mathrm{N}$, and Hochedlinger K (2011) Sox2(+) adult stem and progenitor cells are important for tissue regeneration and survival of mice. Cell Stem Cell 9:317-329.

Avilion AANicolis SK, Pevny LH, Perez L, Vivian N, and Lovell-Badge R (2003) Multipotent cell lineages in early mouse development depend on SOX2 function. Genes Dev 17:126-140.

Blancafort P, Jin J, and Frye S (2013) Writing and rewriting the epigenetic code of cancer cells: from engineered proteins to small molecules. Mol Pharmacol 83: $563-576$.

Bourin P, Bunnell BA, Casteilla L, Dominici M, Katz AJ, March KL, Redl H, Rubin JP, Yoshimura K, and Gimble JM (2013) Stromal cells from the adipose tissuederived stromal vascular fraction and culture expanded adipose tissue-derived stromal/stem cells: a joint statement of the International Federation for Adipose Therapeutics and Science (IFATS) and the International Society for Cellular Therapy (ISCT). Cytotherapy 15:641-648.

Boyer LA, Lee TI, Cole MF, Johnstone SE, Levine SS, Zucker JP, Guenther MG, Kumar RM, Murray HL, and Jenner RG et al. (2005) Core transcriptional regulatory circuitry in human embryonic stem cells. Cell 122:947-956.

Bylund M, Andersson E, Novitch BG, and Muhr J (2003) Vertebrate neurogenesis is counteracted by Sox1-3 activity. Nat Neurosci 6:1162-1168.

Canazza A, Bedini G, Caremoli F, Nava S, Latorre E, Tosetti V, Taiana M, Dossena M, Bersano A, and Pareyson D et al. (2015) A novel efficient method to isolate human adipose-derived stromal cells from periumbilical biopsies without enzymatic digestion. CellR4 3: e1397.

Caplan AI (2007) Adult mesenchymal stem cells for tissue engineering versus regenerative medicine. J Cell Physiol 213:341-347.

Carelli S, Messaggio F, Canazza A, Hebda DM, Caremoli F, Latorre E, Grimoldi MG, Colli M, Bulfamante G, and Tremolada C et al. (2015) Characteristics and properties of mesenchymal stem cells derived from microfragmented adipose tissue. Cell Transplant 24:1233-1252.

Chambers I, Silva J, Colby D, Nichols J, Nijmeijer B, Robertson M, Vrana J, Jones K, Grotewold L, and Smith A (2007) Nanog safeguards pluripotency and mediates germline development. Nature 450:1230-1234.

Chang N, Yi J, Guo G, Liu X, Shang Y, Tong T, Cui Q, Zhan M, Gorospe M, and Wang W (2010) HuR uses AUF1 as a cofactor to promote p16INK4 mRNA decay. Mol Cell Biol 30:3875-3886.

Chi MN, Auriol J, Jégou B, Kontoyiannis DL, Turner JM, de Rooij DG, and Morello D (2011) The RNA-binding protein ELAVL1/HuR is essential for mouse spermatogenesis, acting both at meiotic and postmeiotic stages. Mol Biol Cell 22:2875-2885.

D'Agostino VG, Adami V, and Provenzani A (2013) A novel high throughput biochemical assay to evaluate the HuR protein-RNA complex formation. PLoS One 8: e72426.

Divya MS, Roshin GE, Divya TS, Rasheed VA, Santhoshkumar TR, Elizabeth KE, James J, and Pillai RM (2012) Umbilical cord blood-derived mesenchymal stem cells consist of a unique population of progenitors co-expressing mesenchymal stem cell and neuronal markers capable of instantaneous neuronal differentiation. Stem Cell Res Ther 3:57.

Dominici M, Le Blanc K, Mueller I, Slaper-Cortenbach I, Marini F, Krause D, Deans $\mathrm{R}$, Keating A, Prockop $\mathrm{Dj}$, and Horwitz E (2006) Minimal criteria for defining multipotent mesenchymal stromal cells. The International Society for Cellular Therapy position statement. Cytotherapy 8:315-317.

Ellis P, Fagan BM, Magness ST, Hutton S, Taranova O, Hayashi S, McMahon A, Rao M, and Pevny L (2004) SOX2, a persistent marker for multipotential neural stem cells derived from embryonic stem cells, the embryo or the adult. Dev Neurosci $\mathbf{2 6}$ : 148-165.

Favaro R, Valotta M, Ferri AL, Latorre E, Mariani J, Giachino C, Lancini C, Tosetti V, Ottolenghi S, and Taylor V et al. (2009) Hippocampal development and neural stem cell maintenance require Sox2-dependent regulation of Shh. Nat Neurosci 12: 1248-1256.

Feng N, Han Q, Li J, Wang S, Li H, Yao X, and Zhao RC (2014) Generation of highly purified neural stem cells from human adipose-derived mesenchymal stem cells by Sox1 activation. Stem Cells Dev 23:515-529. 
Friedenstein AJ, Chailakhjan RK, and Lalykina KS (1970) The development of fibroblast colonies in monolayer cultures of guinea-pig bone marrow and spleen cells. Cell Tissue Kinet 3:393-403.

Ghosh M, Aguila HL, Michaud J, Ai Y, Wu MT, Hemmes A, Ristimaki A, Guo C, Furneaux H, and Hla T (2009) Essential role of the RNA-binding protein HuR in progenitor cell survival in mice. $J$ Clin Invest 119:3530-3543.

Gimble JM, Katz AJ, and Bunnell BA (2007) Adipose-derived stem cells for regenerative medicine. Circ Res 100:1249-1260.

Gorospe M, Tominaga K, Wu X, Fähling M, and Ivan M (2011) Post-transcriptional control of the hypoxic response by RNA-binding proteins and microRNAs. Front Mol Neurosci 4:7.

Graham V, Khudyakov J, Ellis P, and Pevny L (2003) SOX2 functions to maintain neural progenitor identity. Neuron 39:749-765.

Gritti A, Bonfanti L, Doetsch F, Caille I, Alvarez-Buylla A, Lim DA, Galli R, Verdugo JM, Herrera DG, and Vescovi AL (2002) Multipotent neural stem cells reside into the rostral extension and olfactory bulb of adult rodents. $J$ Neurosci 22:437-445.

Han DW, Tapia N, Araúzo-Bravo MJ, Lim KT, Kim KP, Ko K, Lee HT, and Schöler HR (2013) Sox2 Level Is a Determinant of Cellular Reprogramming Potential. PLoS One 8:e67594.

Hinman MN and Lou H (2008) Diverse molecular functions of Hu proteins. Cell Mol Life Sci 65:3168-3181.

Huberman E and Callaham MF (1979) Induction of terminal differentiation in human promyelocytic leukemia cells by tumor-promoting agents. Proc Natl Acad Sci USA 76:1293-1297.

Kamachi Y, Uchikawa M, Collignon J, Lovell-Badge R, and Kondoh H (1998) Involvement of Sox1, 2 and 3 in the early and subsequent molecular events of lens induction. Development 125:2521-2532.

Katsanou V, Milatos S, Yiakouvaki A, Sgantzis N, Kotsoni A, Alexiou M, Harokopos V, Aidinis V, Hemberger M, and Kontoyiannis DL (2009) The RNA-binding protein Elavl1/HuR is essential for placental branching morphogenesis and embryonic development. Mol Cell Biol 29:2762-2776.

Kiernan AE, Pelling AL, Leung KK, Tang AS, Bell DM, Tease C, Lovell-Badge R, Steel KP, and Cheah KS (2005) Sox2 is required for sensory organ development in the mammalian inner ear. Nature 434:1031-1035.

Kim HH, Kuwano Y, Srikantan S, Lee EK, Martindale JL, and Gorospe M (2009) HuR recruits let-7/RISC to repress c-Myc expression. Genes Dev 23:1743-1748.

Koba M and Konopa J (2005) [Actinomycin D and its mechanisms of action]. Postepy Hig Med Dosw (Online) 59:290-298.

Lal A, Mazan-Mamczarz K, Kawai T, Yang X, Martindale JL, and Gorospe M (2004) Concurrent versus individual binding of HuR and AUF1 to common labile target mRNAs. EMBO J 23:3092-3102.

Latorre E, Tebaldi T, Viero G, Spartà AM, Quattrone A, and Provenzani A (2012) Downregulation of $\mathrm{HuR}$ as a new mechanism of doxorubicin resistance in breast cancer cells. Mol Cancer 11:13.

Leu YW, Huang TH, and Hsiao SH (2013) Epigenetic reprogramming of mesenchymal stem cells. Adv Exp Med Biol 754:195-211.

Nishi K, Nishi A, Nagasawa T, and Ui-Tei K (2013) Human TNRC6A is an Argonaute-navigator protein for microRNA-mediated gene silencing in the nucleus. RNA 19:17-35

Obrig TG, Culp WJ, McKeehan WL, and Hardesty B (1971) The mechanism by which cycloheximide and related glutarimide antibiotics inhibit peptide synthesis on reticulocyte ribosomes. J Biol Chem 246:174-181.
Okubo T, Pevny LH, and Hogan BL (2006) Sox2 is required for development of taste bud sensory cells. Genes Dev 20:2654-2659.

Park SB, Seo KW, So AY, Seo MS, Yu KR, Kang SK, and Kang KS (2012) SOX2 has a crucial role in the lineage determination and proliferation of mesenchymal stem cells through Dickkopf-1 and c-MYC. Cell Death Differ 19:534-545.

Patel M and Yang S (2010) Advances in reprogramming somatic cells to induced pluripotent stem cells. Stem Cell Rev 6:367-380.

Que J, Okubo T, Goldenring JR, Nam KT, Kurotani R, Morrisey EE, Taranova O, Pevny LH, and Hogan BL (2007) Multiple dose-dependent roles for Sox2 in the patterning and differentiation of anterior foregut endoderm. Development 134: $2521-2531$

Rosenbaum AJ, Grande DA, and Dines JS (2008) The use of mesenchymal stem cells in tissue engineering: A global assessment. Organogenesis 4:23-27.

Shi Y, Do JT, Desponts C, Hahm HS, Schöler HR, and Ding S (2008) A combined chemical and genetic approach for the generation of induced pluripotent stem cells. Cell Stem Cell 2: 525-528.

Sontheimer EJ (2005) Assembly and function of RNA silencing complexes. Nat Rev Mol Cell Biol 6:127-138.

Takahashi K, Tanabe K, Ohnuki M, Narita M, Ichisaka T, Tomoda K, and Yamanaka $\mathrm{S}$ (2007) Induction of pluripotent stem cells from adult human fibroblasts by defined factors. Cell 131:861-872.

Takahashi K and Yamanaka S (2006) Induction of pluripotent stem cells from mouse embryonic and adult fibroblast cultures by defined factors. Cell 126:663-676.

Taranova OV, Magness ST, Fagan BM, Wu Y, Surzenko N, Hutton SR, and Pevny LH (2006) SOX2 is a dose-dependent regulator of retinal neural progenitor competence. Genes Dev 20:1187-1202.

Wang Y, Xu Z, Jiang J, Xu C, Kang J, Xiao L, Wu M, Xiong J, Guo X, and Liu H (2013) Endogenous miRNA sponge lincRNA-RoR regulates Oct4, Nanog, and Sox2 in human embryonic stem cell self renewal. Dev Cell 25(1):69-80.

Yang E, Liu N, Tang Y, Hu Y, Zhang P, Pan C, Dong S, Zhang Y, and Tang Z (2015) Generation of neurospheres from human adipose-derived stem cells. BioMed Res Int 2015:743714.

Yoon JH, Abdelmohsen K, Kim J, Yang X, Martindale JL, Tominaga-Yamanaka K, White EJ, Orjalo AV, Rinn JL, and Kreft SG et al. (2013) Scaffold function of long non-coding RNA HOTAIR in protein ubiquitination. Nat Commun 4:2939.

Yu J, Vodyanik MA, Smuga-Otto K, Antosiewicz-Bourget J, Frane JL, Tian S, Nie J, Jonsdottir GA, Ruotti V, and Stewart R et al. (2007) Induced pluripotent stem cell lines derived from human somatic cells. Science 318:1917-1920.

Zappone MV, Galli R, Catena R, Meani N, De Biasi S, Mattei E, Tiveron C, Vescovi AL, Lovell-Badge R, and Ottolenghi S et al. (2000) Sox2 regulatory sequences direct expression of a (beta)-geo transgene to telencephalic neural stem cells and precursors of the mouse embryo, revealing regionalization of gene expression in CNS stem cells. Development 127:2367-2382

Zucal C, D’Agostino V, Loffredo R, Mantelli B, NatthakanThongon, Lal P, Latorre E, and Provenzani A (2015) Targeting the multifaceted HuR protein, benefits and caveats. Curr Drug Targets 16:499-515.

Address correspondence to: Stephana Carelli or Elisa Latorre, Laboratory of Pharmacology, Department of Health Sciences, University of Milan, Via Antonio Di Rudinì 8, Milan 20142, Italy. E-mail: stephana.carelli@guest.unimi. it or elisa.latorre@unimi.it 